\title{
New Method for Assaying Free and Total Cholesterol in Cultured Cells by High-pressure Liquid Chromatography
}

\author{
Kozo Hayashi, Yoshio Kuga, Yoshifumi Okura, Kouichi Tanaka, Yuji Yasunobu, Katsuhiko \\ Nomura, Yasushi Toyota, Harumi Ohtani, Tetsuji Shingu, and Goro Kajiyama
}

First Department of Internal Medicine, Hiroshima University School of Medicine, Hiroshima, Japan.

\begin{abstract}
We developed a simple, sensitive and accurate method for assaying cellular free and total cholesterol by monitoring 4-cholesten-3-one, a conversion product of the cholesterol oxidasecatalyzed oxidation of the free cholesterol that has a strong chromophoric $\alpha, \beta$-unsaturated ketone at $240 \mathrm{~nm}$, using a high-pressure liquid chromatographic system. This method measured picomole quantities of free and total cholesterol and precisely determined their concentrations in cells ( $10^{4}$ range) in culture using $7 \beta$-hydroxycholesterol as an internal standard. $J$ Atheroscler Thromb, 1996 ; 2 : $117-121$.
\end{abstract}

Key words: Cholesterol, 4-cholesten-3-one, $7 \beta$-hydroxy-4-cholesten-3-one, High-pressure liquid chromatography, Cultured cells

An easy and sensitive enzymatic fluorometric method, based on the measurement of the final fluorescent product by reaction with cholesterol esterase, cholesterol oxidase, horseradish peroxidase, and p-hydroxyphenylacetic acid, for the determination of total or free cholesterol in cultured cells has been described (1).

The compound 4-cholesten-3-one, formed by the cholesterol oxidase-catalyzed oxidation of free cholesterol, exhibits an intense absorption at $240 \mathrm{~nm}$. This property has been applied to the high-pressure liquid chromatographic (HPLC) measurement of $7 \alpha$-hydroxy-4-cholesten-3-one, which also has an intense absorption at $240 \mathrm{~nm}$; the compound is formed by the cholesterol oxidase-catalyzed oxidation of 5cholesten-3 $\beta, 7 \alpha$-diol (7 $\alpha$-hydroxycholesterol) $(2,3)$.

We determined whether HPLC monitoring at $240 \mathrm{~nm}$ of 4 cholesten-3-one, a conversion product of the cholesterol oxidase-catalyzed oxidation of free cholesterol, could be used for the accurate and sensitive determination of free cholesterol and esterified cholesterol hydrolyzed by choles-

Address for correspondence: Kozo Hayashi, M.D., First Department of Internal Medicine, Hiroshima University School of Medicine, 1-2-3 Kasumi, Minami-ku, Hiroshima 734, Japan. Received March 14, 1995.

Accepted for publication May 17, 1995

Abbreviations: DMEM; Dulbecco's Modified Eagle Medium, HPLC; high-pressure liquid chromatography. terol esterase in cultured cells. As the internal standard, we used $7 \beta$-hydroxy-4-cholesten-3-one, a conversion product of the cholesterol oxidase-catalyzed oxidation of 5-cholesten-3 $\beta, 7 \beta$-diol ( $7 \beta$-hydroxycholesterol) to develop a more accurate assay system by correcting for any variation of recovery of cholesterol during the procedure.

\section{Materials and Methods}

\section{Chemicals}

Cholesterol oxidase from Rhodococcus erythropolis (25 units $/ \mathrm{mg}$ ) was obtained from Boehringer Mannheim $\mathrm{GmbH}$ (Mannheim, Germany). Cholesterol esterase from Pseudomonas sp. (19 units/mg), sodium taurocholate, sodium phosphate (mono and dibasic) and Triton X-100 (reagent grade) were obtained from Wako Pure Chemical Indust., $L$. (Osaka, Japan). Cholesterol, cholesteryl oleate, and $7 \beta-$ hydroxycholesterol (chromatographic grade) were obtained from Sigma Chemical Co. (St. Louis, MO, USA). n-Hexane, 2-propanol, methanol, and petroleum ether (HPLC grade) were obtained from Wako Pure Chemical Indust., L. Hep G2 cells were obtained from American Type Culture Collection (Rockville, Maryland, USA).

\section{Cell extraction procedure}

Each cell monolayer $\left(10^{4}\right.$ cells) incubated with DMEM containing $10 \%$ fetal bovine serum, $100 \mathrm{IU} / \mathrm{ml}$ of penicillin, 
and $100 \mu \mathrm{g} / \mathrm{ml}$ of streptomycin in a 35- $\mathrm{mm}$ petri dish was washed twice with phosphate-buffered saline $(\mathrm{NaCl} 8.0 \mathrm{~g} / \mathrm{L}$, $\mathrm{KCL} 0.2 \mathrm{~g} / \mathrm{L}, \mathrm{Na}_{2} \mathrm{HPO}_{4} 1.15 \mathrm{~g} / \mathrm{L}, \mathrm{KH}_{2} \mathrm{PO}_{4} 0.2 \mathrm{~g} / \mathrm{L}, \mathrm{CaCl}_{2} 0.1 \mathrm{~g} /$ $\left.\mathrm{L}, \mathrm{MgCl}_{2} .6 \mathrm{H}_{2} \mathrm{O} 0.1 \mathrm{~g} / \mathrm{L}\right)$, then after the addition of $40 \mathrm{nmol}$ of $7 \beta$-hydroxycholesterol in 2-propanol and $1 \mathrm{ml}$ of $\mathrm{n}$-hexane/ 2 -propanol $(3: 2, \mathrm{v} / \mathrm{v})$, incubated for $30 \mathrm{~min}$ at room temperature, as described previously (4). The organic solvent was removed, each monolayer was rinsed briefly with $0.5 \mathrm{ml}$ of the solvent mixture described above, and the two organic solvent extracts were combined in a glass tube. The solvent was evaporated to dryness and the lipids in each tube were resuspended in $200 \mu \mathrm{l}$ of $\mathrm{n}$-hexane/2-propanol $(3: 2$, $\mathrm{v} / \mathrm{v})$. Aliquots $(5 \mu \mathrm{l})$ were used for assay of free and total cholesterol, as described below. After the lipids had been extracted in situ from the petri dish, the cells in each monolayer were dissolved in $1 \mathrm{~N} \mathrm{NaOH}$ and aliquots were used for protein determination by the Lowry procedure (5).

Assay by HPLC of 4-cholesten-3-one, a conversion product of the cholesterol oxidase-catalyzed oxidation of free cholesterol, with $7 \beta$-hydroxy-4-cholesten-3-one used as an internal standard

Conversion of cholesterol and $7 \beta$-hydroxycholesterol to 4- cholesten-3-one and 7 $\beta$-hydroxy-4-cholesten-3-one, by cholesterol oxidase was carried out according to a slight modification of a published method (1). In brief, the incubation mixture contained $0.05 \mathrm{M}$ sodium phosphate buffer $(\mathrm{pH}$ 7.0), 0.25 units of cholesterol oxidase, $5 \mathrm{mM}$ sodium taurocholate (Buffer A), and authentic free cholesterol and $7 \beta$ hydroxycholesterol in a final volume of $0.4 \mathrm{ml}$. A 2propanol solution of authentic free cholesterol and of $7 \beta$ hydroxycholesterol (each $10 \mu \mathrm{l}$ ) was added to the incubation mixture. The procedure described for assay of free cholesterol was followed for assay of total cholesterol, except that the incubation mixture contained $0.05 \mathrm{M}$ sodium phosphate buffer ( $\mathrm{pH} 7.0$ ), 5 units of cholesterol esterase, 0.25 units of cholesterol oxidase, $5 \mathrm{mM}$ sodium taurocholate, $0.05 \%$ Triton X-100 (Buffer B), and authentic cholesteryl oleate and $7 \beta-$ hydroxycholesterol in a final volume of $0.4 \mathrm{ml}$. A 2-propanol solution of authentic cholesteryl oleate $(10 \mu \mathrm{l})$ was added to the incubation mixture. After a $30-$ min incubation at $37^{\circ} \mathrm{C}$ with vigorous shaking, the reaction was terminated by the addition of $0.4 \mathrm{ml}$ of methanol, and the mixture was extracted with $4 \mathrm{ml}$ of petroleum ether. The extract was evaporated to dryness, and the residue was dissolved in $50 \mu \mathrm{l}$ of $\mathrm{n}-$ hexane/2-propanol $(80: 20, \mathrm{v} / \mathrm{v})$, an aliquot was analyzed by
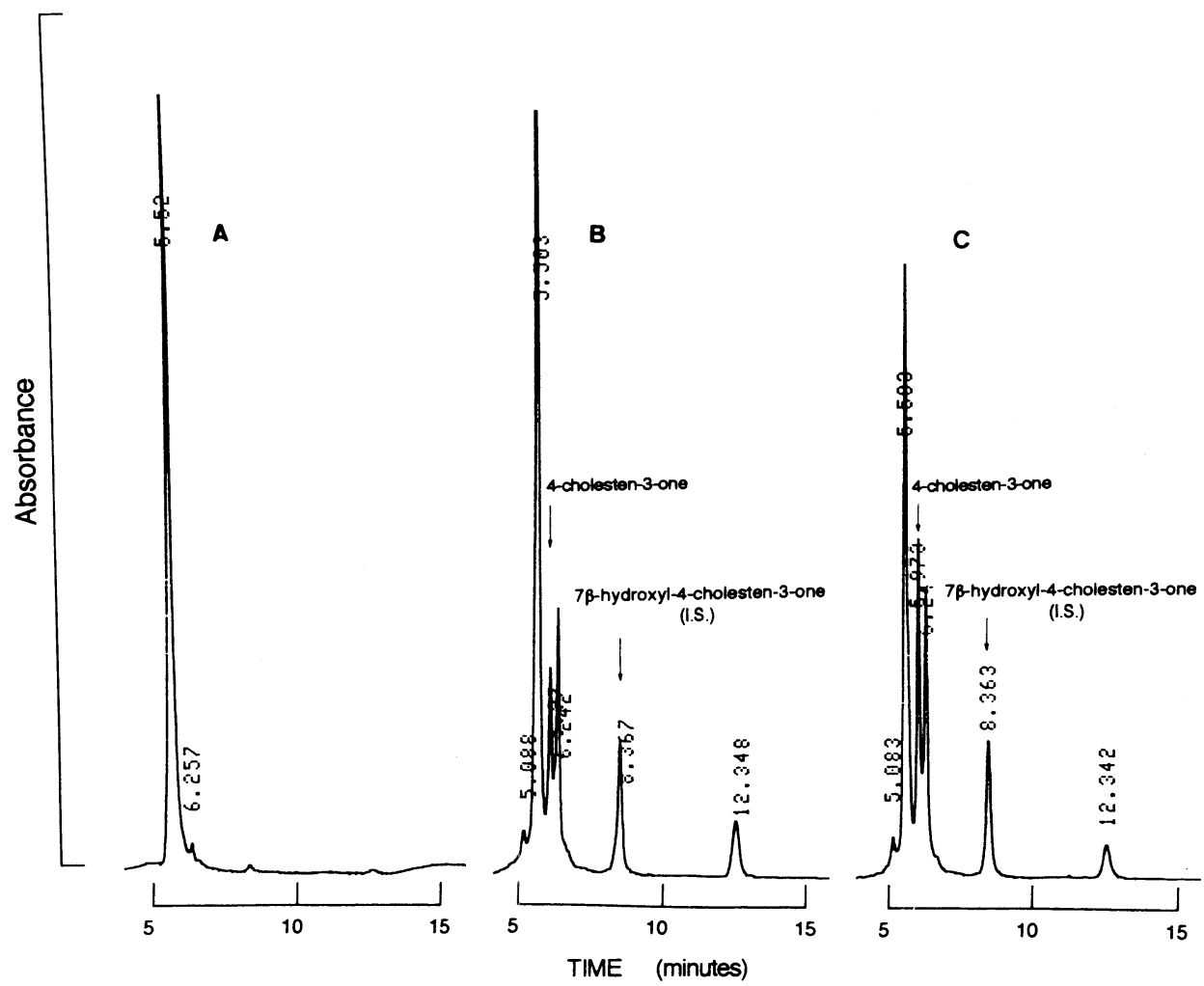

Fig. 1. Chromatograms of 4-cholesten-3-one and $7 \beta$-hydroxy-4-cholesten-3-one produced in the free cholesterol assay system. For the free cholesterol assay system, $100 \mathrm{pmol}(\mathrm{B})$ or 200 $\mathrm{pmol}(\mathrm{C})$ of authentic free cholesterol was incubated with $100 \mathrm{pmol}$ of authentic $7 \beta$-hydroxycholesterol in the mixture. The products were analyzed as described in Materials and Methods. A blank (A) was assayed as described in Results. 
normal phase HPLC on a Zorbax-Sil column $(0.25 \mathrm{~m} \times 4.6$ $\mathrm{mm}$, Shimadzu-Dupont Co. L., Kyoto, Japan). The column was eluted with a mixture of $n$-hexane and 2-propanol $(80$ : $20, \mathrm{v} / \mathrm{v}$ ) at a rate of $0.6 \mathrm{ml} / \mathrm{min}$. Absorbance of the effluent at $240 \mathrm{~nm}$ was monitored. The HPLC system consisted of an injector, a pump equipped with a UV spectrophotometer, and an integrator (Shimadzu Co., L., Kyoto, Japan).

Free cholesterol and total cholesterol extracted in situ from the petri dish were assayed as described above after being converted to 4-cholesten-3-one in incubation Buffer $A$ and $B$, respectively. Usually, $5 \mu \mathrm{l}$ of extracted lipid suspended in $200 \mu \mathrm{l}$ of $\mathrm{n}$-hexane/2-propanol $(3: 2, \mathrm{v} / \mathrm{v})$ was used for these enzymatic reactions.

\section{Results}

\section{Chromatographic profiles of extract of the reaction mixture}

Authentic free cholesterol (100 or $200 \mathrm{pmol}$ ) or cholesteryl oleate ( 100 or $200 \mathrm{pmol})$, on the one hand, and $7 \beta$-hydroxycholesterol $(100 \mathrm{pmol})$, on the other, were converted to $4-$ cholesten-3-one and 7 $\beta$-hydroxy-4-cholesten-3-one, respectively, in the reaction mixture. Extracts were subjected to HPLC. Cholesterol oxidase and cholesterol esterase effectively converted cholesterol, cholesteryl oleate to 4cholesten-3-one and $7 \beta$-hydroxycholesterol to $7 \beta$ hydroxy-4-cholesten-3-one under these incubation conditions, as described previously $(1,2)$. Figure 1 shows the typical chromatographic profiles of 4-cholesten-3-one and $7 \beta$-hydroxy-4-cholesten-3-one produced in the reaction mixture for the free cholesterol assay system. The peak substances having retention times of 5.97 and $8.36 \mathrm{~min}$ were 4-cholesten-3-one and 7 $\beta$-hydroxy-4-cholesten-3-one, respectively. The origin of the peak substances having retention times of $5.50,6.24$, and 12.34 min was not identified. Chromatographic profiles of a blank also showed peak substances with retention times of 5.52, 6.25, and 12.34 min (Fig. 1A); the blank contained lipids extracted from the reaction mixture containing Buffer $A$ and authentic free cholesterol (200 pmol) and 7 $\beta$-hydroxycholesterol (100 pmol) that had been incubated for 0 min. Figure 2 shows the typical chromatographic profiles of 4-cholesten-3-one and $7 \beta$-hydroxy-4-cholesten-3-one produced in the reaction mixture for the esterified cholesterol assay system. Chromatographic profiles of a blank showed unidentified peak substances having retention times of $5.08,5.50,6.23$, 7.01, 8.93, and 12.45 min (Fig. 2A). The blank contained lipids extracted from the reaction mixture containing Buffer $B$ and authentic cholesteryl oleate $(200 \mathrm{pmol})$ and $7 \beta$ hydroxycholesterol $(100 \mathrm{pmol})$ that had been incubated for 0 min. Peaks of 4-cholesten-3-one and $7 \beta$-hydroxy-4cholesten-3-one having retention times of 5.96 and $8.35 \mathrm{~min}$ were also separated, without interference by other peaks in this assay system (Figs. 2B, C).

\section{Linearity of standard curve}

The results of quantitation of cholesterol and cholesteryl oleate after their conversion to 4-cholesten-3-one were plotted with $7 \beta$-hydroxy-4-cholesten-3-one, a conversion product of $7 \beta$-hydroxycholesterol, as an internal standard.

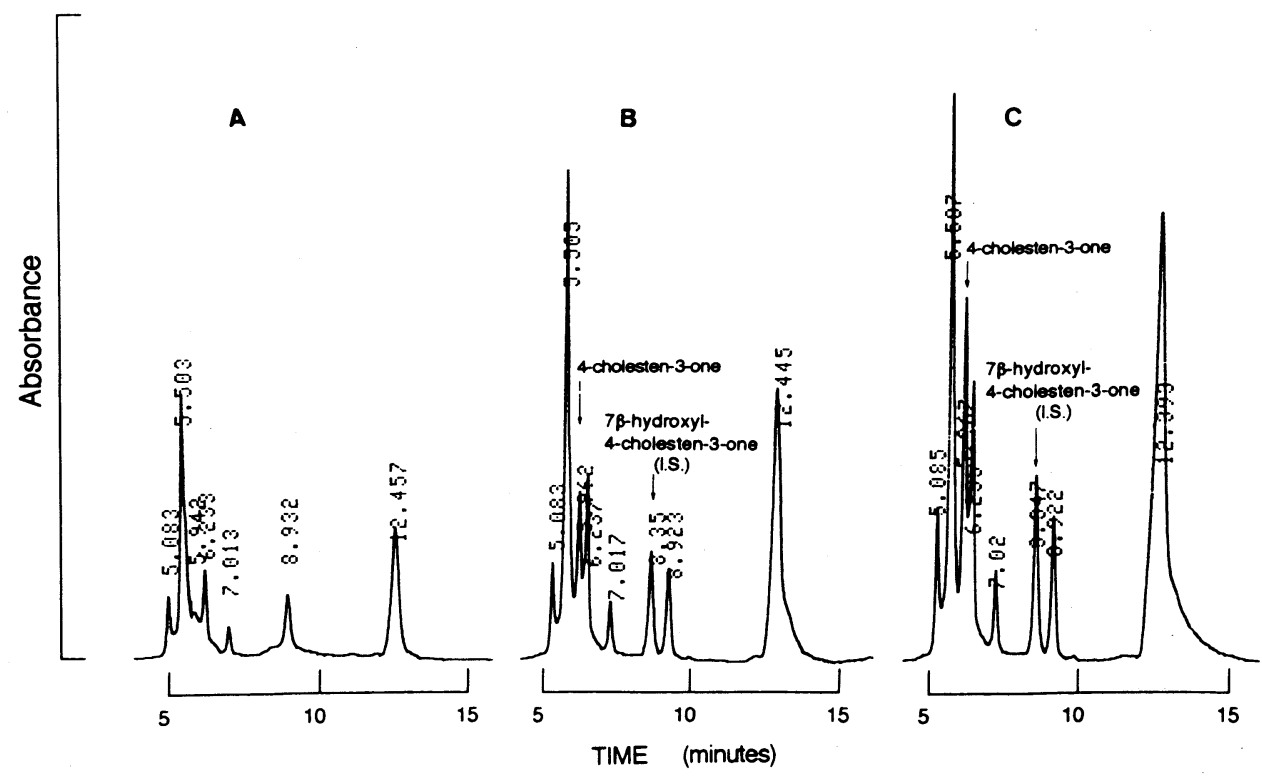

Fig. 2. Chromatograms of 4-cholesten-3-one and $7 \beta$-hydroxy-4-cholesten-3-one produced in the esterified cholesterol assay system. For the esterified cholesterol assay system, $100 \mathrm{pmol}(\mathrm{B})$ or $200 \mathrm{pmol}$ (C) of authentic cholesteryl oleate were incubated with $100 \mathrm{pmol}$ of $7 \beta$-hydroxycholesterol in the mixture. The products were analyzed as described in Materials and Methods. A blank (A) was assayed as described in Results. 
$7 \beta$-hydroxy-4-cholesten-3-one ( $100 \mathrm{pmol})$ was used as an internal standard in this assay. The calculated amounts of 4-cholesten-3-one had a linear relationship to the amounts of authentic free cholesterol and cholesteryl oleate within 1,000 pmol (Fig. 3).

\section{Measurement of free and total cholesterol extracted in situ from cultured monolayers}

Free and total cholesterol extracted from cultured HepG2 cells were measured with $7 \beta$-hydroxycholesterol as an internal standard by HPLC after their conversion to 4-cholesten3-one and $7 \beta$-hydroxy-4-cholesten-3-one, respectively.
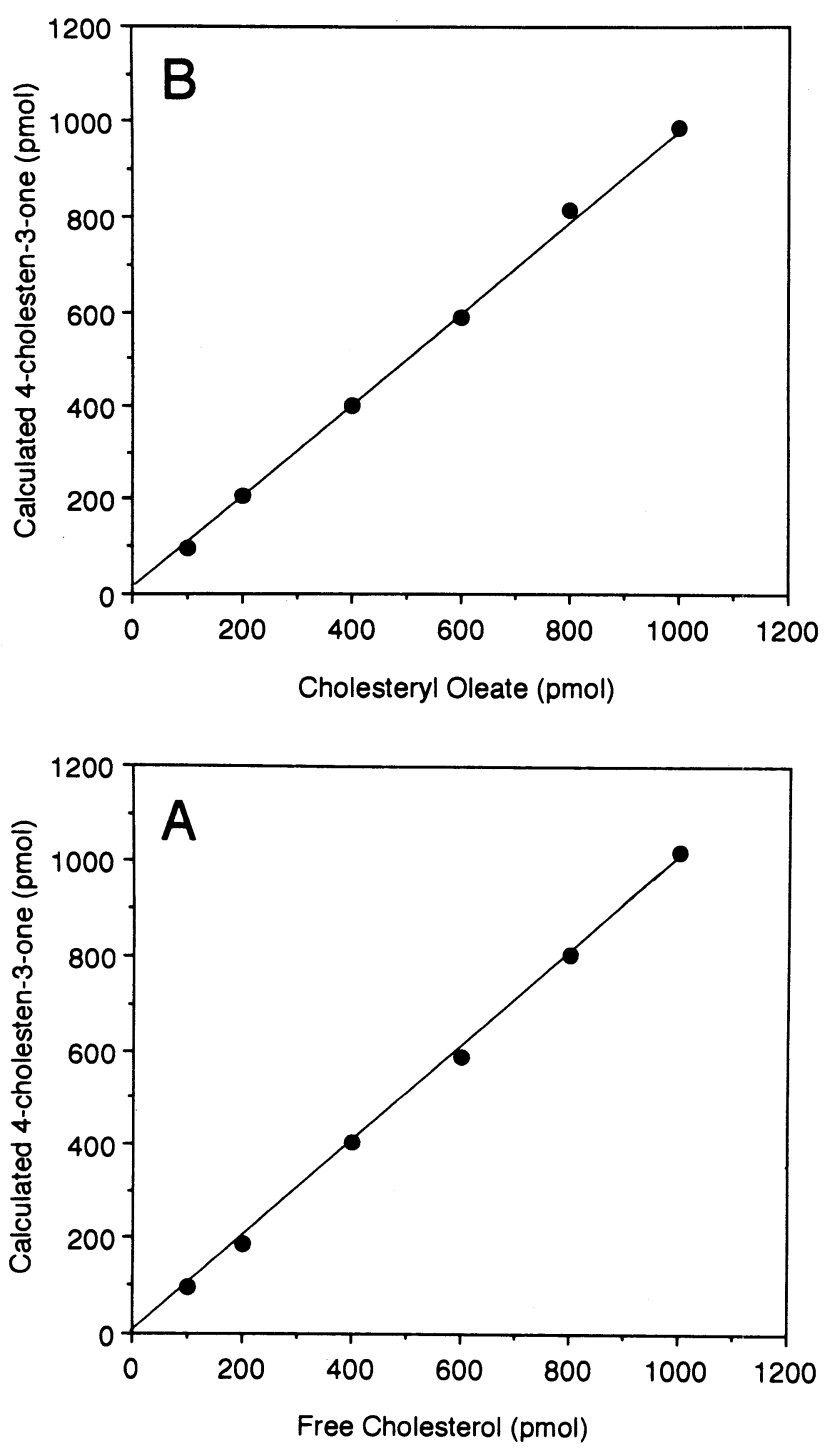

Fig. 3. Calibration curves for 4-cholesten-3-one. Various amounts of authentic free cholesterol (A) or cholester$\mathrm{yl}$ oleate $(B)$ were incubated with $100 \mathrm{pmol}$ of authentic $7 \beta$-hydroxycholesterol used as an internal standard in the mixture for the free or esterified cholesterol assay system. The products were analyzed as described in Materials and Methods.

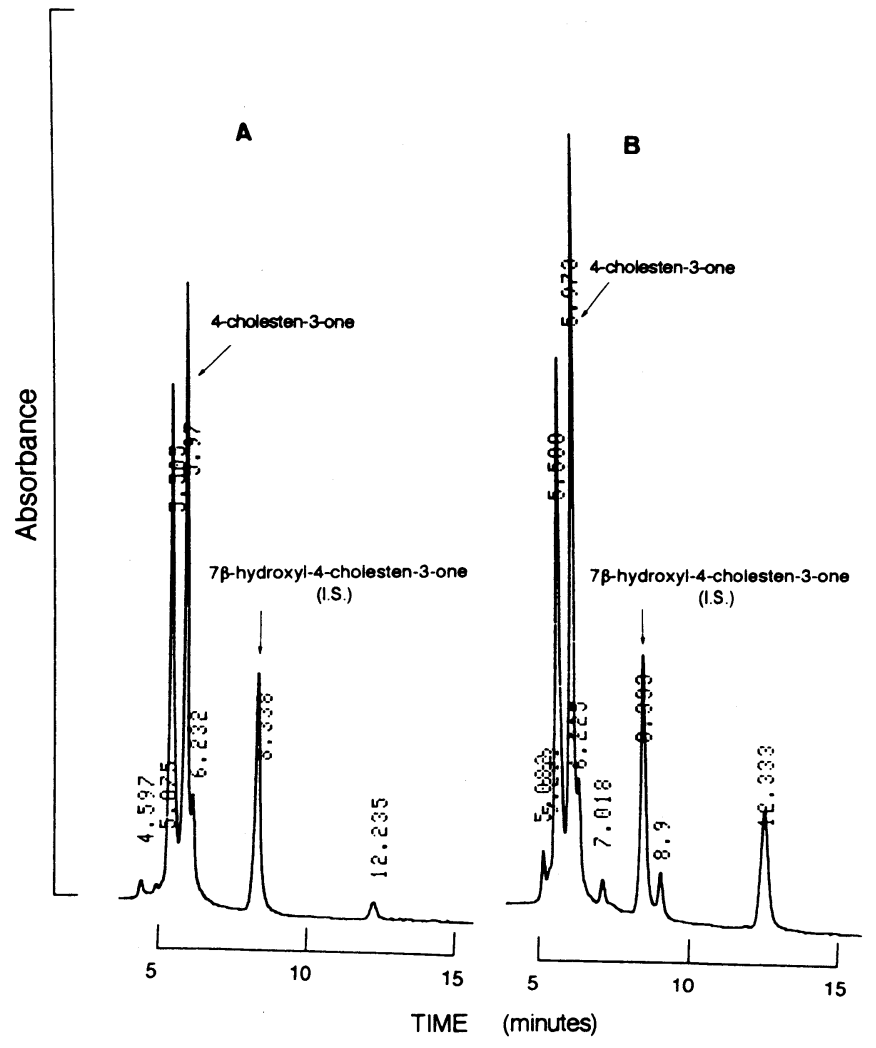

Fig. 4. Chromatograms of 4-cholesten-3-one and $7 \beta$ hydroxy-4-cholesten-3-one produced in the free or esterified cholesterol assay system incubated with lipids extracted in situ from cultured HepG2 cells. Lipids extracted in situ from cultured HepG2 cells containing $7 \beta$-hydroxycholesterol as an internal standard were incubated with the free (A) or esterified cholesterol (B) assay mixture. The products were analyzed as described in Materials and Methods.

Table 1. Reproducibility of the method for cholesterol assay.

\begin{tabular}{ccc}
\hline $\begin{array}{c}\text { Experiment } \\
\text { number }\end{array}$ & $\begin{array}{c}\text { Free } \\
\text { cholesterol } \\
(\mathrm{nmol} / \mathrm{mg} \text { of }\end{array}$ & $\begin{array}{c}\text { Total } \\
\text { protein) }\end{array}$ \\
\hline 1 & $390 \pm 12$ & $489 \pm 27$ \\
2 & $379 \pm 16$ & $485 \pm 18$ \\
3 & $385 \pm 19$ & $493 \pm 12$ \\
\hline
\end{tabular}

Values are mean \pm standard deviation (SD) of the results for each day of measurement. Each assay was repeated at least five times. 
As shown in Fig. 4, peaks of 4-cholesten-3-one and $7 \beta$ hydroxy-4-cholesten-3-one having retention times of 5.97 and $8.33 \mathrm{~min}$, respectively, were separated by the free and total cholesterol assay systems. Table 1 shows the calculated means and standard deviations for cellular free and total cholesterol. Data obtained by this method were reproducible (Table 1).

\section{Discussion}

The investigation of metabolic changes in cholesterol induced by drugs, lipoproteins, hormones, growth factors, and cytokines in various types of cultured cells requires a sensitive and accurate assay system for cellular free and total cholesterol.

Reports that the cholesterol oxidase-catalyzed oxidation of free cholesterol yields 4-cholesten-3-one (1), that $7 \alpha$ hydroxy-4-cholesten-3-one, a product of the cholesterol oxidase-catalyzed oxidation of $7 \alpha$-hydroxycholesterol, carries a strong chromophoric group $(\alpha, \beta$-unsaturated ketone), and that one can determine picomole concentrations of $7 \alpha$-hydroxycholesterol by HPLC (2) prompted us to develop an accurate and sensitive assay system for cellular cholesterol by HPLC. For this purpose, we used $7 \beta$ hydroxycholesterol as an internal standard in the HPLC system, as described previously (3).

By the present assay system we could determine picomole concentrations of free and total cholesterol (Figs. 1-3) and it was applicable to the assay of the free and total cholesterol content of monolayers in culture $\left(10^{4}\right.$ cells) (Fig. 4). The sensitivity of monitoring $\alpha, \beta$-unsaturated ketone was equivalent to that of the enzymatic fluorometric method previously described (1). The advantage of this new method is its precision in the assay of free and total cholesterol extracted in situ from cultured monolayers that is attained by the use of an internal standard. In this way, assay errors due to the process of lipid extraction and the handling of small amounts of extracted samples dissolved in organic solvent can be corrected, making the assay more accurate.

The assay system for free and total cholesterol described here provides a simple, sensitive, and accurate determination of the cholesterol content of cells $\left(10^{4}\right.$ range) in culture.

\section{References}

(1) Heider JG and Boyett RL: The picomole determination of free and total cholesterol in cells in culture. J Lipid Res, 19: 514-518, 1978

(2) Ogishima T and Okuda K: An improved method for assay of cholesterol $7 \alpha$-hydroxylase activity. Anal Biochem, 158: 228-232, 1986

(3) Hayashi K, Kurushima H, Saeki M, Amioka H, Kurokawa J, Kuga $Y$, Nomura $S$, Ohkura $Y$, Ohtani $H$, Noshiro $M$, and Kajiyama G: Partial cloning of cDNA for hamster liver cholesterol $7 \alpha$-hydroxylase. Intern Med, 32: 210-214, 1993

(4) Goldstein JL, Basu SK, and Brown MS : Receptor-mediated endocytosis of low-density lipoprotein in cultured cells. Methods Enzymol, 98: 241-260, 1983

(5) Lowry OH, Rosebrough NJ, Farr AL, and Randall RJ : Protein measurement with the Folin phenol reagent. J Biol Chem, 193: 265-275, 1951 